\title{
Research on Financial Support to Rural Economy in Nantong City
}

\author{
Feng Jin \\ Business College \\ Yangzhou University \\ Yangzhou, China 225000
}

\begin{abstract}
In recent years, Nantong city has made great efforts to solve the problems of imbalance in the allocation of financial resources in urban and rural areas, and it has made great progress. It gives full play to the finance in promoting rural economic development with strengthening the guidance and support. However, some financial institutions are not strong enough to support agriculture, and the structure of financial support to agriculture needs to be optimized. The financial risk diversification and transfer function needs to be improved, and the financial environment and the construction of financial system need to be strengthened. In view of the above problems, it is suggested to construct a multi-level rural financial institution system with coordination and distribution of responsibilities, functional complement and efficient operation. It should closely integrate with the actual development of rural economy in Nantong; identify key areas and key links of financial support to agriculture. It also should make the innovation of rural financial products and improve the financial services. And it can strengthen the construction of agricultural insurance service system to speed up the formation of policy-based and commercial insurance institutions. It can build the agricultural insurance system with the significant security function. In order to better play the role of financial support on agriculture, it should strengthen the guidance and create a good environment for the rural financial system and credit.
\end{abstract}

\section{Keywords-financial support; Nantong city; rural economy}

\section{INTRODUCTION}

There are abundant agricultural resources and good foundation of agricultural production in Nantong. The development of modern agriculture has great potential and promising prospect. During the 12th five-year plan period, Nantong speeded up the construction of modern agricultural industry system, agricultural science and technology innovation system, agricultural infrastructure system, agricultural social service system and agricultural support and protection system to ensure the effective supply of agricultural products, improve the living standards of farmers and promote sustainable development of agriculture. It strived to promote the agricultural modernization, and then it had achieved remarkable results.

To achieve the overall well-off construction, rural areas are the main and difficult points. It needs a comprehensive, three-dimensional support system to promote the development of rural economy in Nantong. Finance is the core of modern economy. The rural development can't be separated from financial support. And financial is an important mechanism to promote rural economic development and institutional arrangements. It plays an irreplaceable role. It can effectively promote the development of modern agriculture in Nantong through the full play of modern financial functions.

\section{ANALYSIS ON THE CURRENT SitUATION OF FINANCIAL SUPPORT TO RURAL ECONOMY IN NANTONG CITY}

\section{A. To Optimize the Environment of Financial Support to Agriculture}

In recent years, the Nantong municipal government has introduced a series of financial policies and measures to support the development of modern agriculture. The relevant departments also have held several conferences to promote the financial support to the modern agricultural. And it they also have made supervision on the supports of financial institutions to agriculture. The districts and counties under Nantong set up a rural comprehensive property rights trading center, and also set up three major service platforms including comprehensive rural property rights transactions, property management and property financing.

\section{B. To Strengthen the Financial Support to Agriculture}

In Nantong, the People's Bank and financial office actively guide the financial institutions to explore new models to support the finance of agriculture, farmer and rural areas. And they have increased the supports to the development of rural infrastructure construction, agricultural leading enterprises and rural society. Nantong Branch of Agricultural Development Bank plays a guiding role in policy-oriented financial support to agricultural enterprises to expand the scale of production, product upgrade and industrial chain extension. The rural commercial banks in Nantong effectively play the role of the main force to support agriculture, to develop micro-credit business, and actively carry out notarial mortgage loans, third-party supervision of movable property pledge loans, collective land mortgage loans, forest mortgages and other business. Commercial banks have also actively expanded rural credit business, and have improved the credit management system of agriculture farmer and rural area 


\section{To Innovate the Mortgage Methods Constantly}

In order to solve the difficulties in the financing of agricultural production and management and the difficulties in mortgage, the financial institutions have carried out many useful practical explorations in Nantong. For example, Nantong Branch of Agricultural Bank rolls out the fishing boats' horsepower mortgage loan for fishermen to provide the working capital to make the renovation of the fishing vessels. And this service may alleviate the fishermen's financial needs to repair ship, repair network and repair machinery in the fishing moratorium.

\section{ANALYSIS ON THE FINANCIAL SUPPORT TO THE RURAL ECONOMY IN NANTONG CITY}

\section{A. The System of Rural Financial Institutions Needs to Be Improved}

In terms of traditional financial institutions, the cost of capital source for China Agriculture Development Bank is high, and the business is limited. And the policy function of serving the rural economy is obviously missing. The credit funds of Agricultural Bank of China have the trends in urbanization, industrialization. And the function of agricultural service has weakened. Rural credit cooperatives and rural commercial banks also have the pursuit of profit targets to achieve risk assessment indicators and other requirements. In this way, the ordinary farmers, rural individual industrial and commercial households are difficult to get loans. With the constraint of cost, efficiency, risk and other factors, other commercial banks also set up little outlets in the grass-roots township to provide financial services. In the terms of new rural financial institutions such as village banks and small loan companies, the main problems faced by these rural financial institutions can be divided into two concepts. First, the sustainability of agricultural credit funds is difficult to guarantee. Second, due to management level, technical level, quality of personnel, business scope and other factors, the sustainability of the development of some financial institutions is not good. And then, the sustainable development of rural economy in Nantong is restricted.

\section{B. The Structure of Rural Financial Support to Agriculture Needs to Be Improved}

At present, the structure of rural financial demands in Nantong has taken great changes, and the rural financial department can't fully adapt and calmly deal with these changes. These changes can be divided into several concepts.

- The support to the new agricultural management is not enough.

- The financial innovation is not enough. The rural financial products and services have many problems. And they are still mainly concentrated in the credit business.

- Many rural financial institutions subjectively hope to further expand the urban financial services.

In this way, it has intensified the contradiction between the supply and demand of fund in the rural economic development in Nantong.
C. The Diversification and Transfer of Rural Financial Risk Needs to Be Improved

- On the status quo of agricultural insurance in Nantong, the development of agricultural insurance lags behind the needs of rural economic development. Agricultural insurance technology is complex, and the rate of compensation is high. And it results in the lack of enthusiasm and motivation of commercial insurance companies. At the same time, the lack of agricultural policy insurance companies is difficulty. In addition, and the awareness of rural residents is not strong.

- The lack of effective collateral for rural economic entities. One of the important reasons for the financing of small and medium-sized enterprises in rural areas is the deficiency of effective collateral assets. And loan guarantees are difficult to implement However, most are only in a small scale or for specific subjects, as well as the promotion of individual products. At the same time, due to the high cost of the guarantee, it also has the risk of mutual security and other security problems. And then, it results the "fear" psychological in the financial departments. So some rural economic entities are shut out.

\section{The Construction of Rural Credit System Needs to Be Strengthened}

At present, the construction of rural credit information database in Nantong is not perfect. The credit information collection standard of rural credit is not unified. The information is difficult to share in different financial departments. And the basic information of farmers and enterprises in finance, land, agriculture, forestry and other departments has not yet completely added to the credit information file of the credit main body. Nantong carries out the assessment of credit township, credit farmers, credit enterprise. To some extent, it is conducive to the promotion of rural credit environment. However, if the assessed and trustworthy subject can't get real preferential treatment in the financial services, the actual incentive effect of the work will be discounted.

\section{COUNTERMEASURES AND SUGGESTIONS ON PROMOTING FINANCIAL SUPPORT TO THE DEVELOPMENT OF RURAL ECONOMY IN NANTONG CITY}

\section{A. To Increase the Effective Supply of Rural Finance}

It should encourage the large state-owned commercial financial institutions to pay attention to the funding needs of agricultural industrialization leading enterprises, agricultural science and technology parks and the rural construction of infrastructure in Nantong. It should broaden the field of agricultural development banking asset management, and vigorously support the rural high-tech industry, the construction of rural infrastructure, the promotion of agricultural science and technology and comprehensive agricultural development and rural ecological environment construction in Nantong. It gives full play to its policy financial function. Also, it can improve the efficiency in 
supporting to agriculture of rural credit cooperatives, agricultural firms and other main forces. On the one hand, it can consolidate and develop traditional business, pay close attention to deposits, increase agricultural credit. In particular, it can increase farmers' micro credit loans and farmers' loans, expand the amount of single-family loans and the coverage of loans, determine the loan period and slow down the loan procedures. On the other hand, it should expand innovation business. According to their actual needs and the rural market demands of Nantong, it can actively set up a variety of agency business, improve the development of settlement and payment means of new business, and develop rural consumer credit, personal finance, consulting business and other businesses. At the same time, it should speed up the construction of their own electronic information system with the Internet development trend. And then, it formed a complete payment transaction settlement system and financial information system. It should support the village banks, small loan companies and farmers mutual aid group to be bigger and stronger. And it constantly improves the business, technology, management level. Then it promotes the local rural economic development through its own sustainable development.

\section{B. To Support Key Areas and Links}

On the axis of modern agriculture, it should identify key areas and links to achieve the efficiency of maximum service with rural economy, social development advantages and characteristics of Nantong. The first is to increase the financial support to standard and large-scale production. The second is to increase the financial support to the national, provincial agricultural industrialization demonstration base (park), which is the leading industry, agglomeration effect is obvious, the industrial chain is integrity, and radiation-driven ability is improved. The third is to increase the financial support to the leading enterprises with radiation capacity, to support key leading enterprises to speed up the development of new technologies, the development and application of new technology research, and to promote product upgrades and cultivate a number of well-known agricultural products brand. The fourth is to increase the financial support to the integration of three industries, to support the extension of the agricultural industry chain upstream and downstream, to achieve the integration of production, supply and marketing, planting. And then, it would raise one - stop services of development. The fifth is to increase the financial support to the construction of rural infrastructure in Nantong, to pay attention to the construction of farmland water conservancy, the reconstruction of low-yielding field, the reconstruction of rural road network, the construction of agricultural products integrated market and logistics base and other aspects of credit needs.

\section{To Innovate the Financial Service Model}

And it should actively promote the agricultural industry chain to innovate the financial service model in Nantong. It can be divided into several aspects. Firstly, the leading agricultural enterprises in the industrial chain are regarded as the center. There are several models: financial institutions + leading enterprises + farmers", "financial institutions + local government + leading enterprises + farmers", "financial institutions + leading enterprises + cooperatives + farmers". It can provide the financial services to the leading enterprises. At the same time, it should also provide comprehensive financial services for its upstream and downstream enterprises or farmers. Secondly, the circulation of agricultural products is the center. It uses the model that financial institutions + agricultural products circulation enterprises + production enterprises + farmers + base. It increases the financial services around the fund flow of upstream and downstream of agricultural products, information flow and commodity flow. Thirdly, the largescale professional market for agricultural products is the center. It uses the model financial institutions + professional market + business + company + farmers. According to the establishment of close cooperation among the financial departments and agricultural product professional markets, businesses, agricultural enterprises, cooperatives, farmers, bases and professional associations, it finally achieves the basic services to the rural economic entities.

\section{To Enrich Rural Financial Service Products}

It can establish a guiding fund through the government to attract the relevant investment institutions and social capital to support the development of agricultural science and technology enterprises and agricultural science and technology parks in Nantong. It should guide the leading agricultural enterprises and farmer professional cooperatives to use the futures market hedging and risk management to reduce market risk. It can make full use of rural small and medium-sized financial institutions rooted in the local. And it can promote the grid financial model, and expand the coverage of micro-credit and UNPROFOR credit loans to better meet the needs of small farmers in general. And it can play the financing function of capital market to promote the agricultural enterprises listed in the domestic and foreign capital markets in Nantong. The agriculture-related enterprises use debt financing tools to encourage qualified enterprises to make stock issues and trust products, and broaden the financing channels. It should give full play to the Internet technology in the field of rural financial services with the help of information technology. And then, it can promote the introduction of rural economic needs for the main credit, settlement, and investment products. Also, it reduces financing costs and improves the comprehensive benefits of funds.

\section{E. To Improve the Agricultural Risk Sharing Mechanism}

It should actively guide and encourage the financial institutions to innovate differentiated collateral security methods. For agricultural science and technology enterprises, it can explore the innovation of trademark, patent, proprietary technology, equity and other collateral. For the leading agricultural enterprises, it should mainly consider the operating income, accounts receivable, orders, inventory, land use rights, large equipment as collateral. And it can actively improve the service network and collateral measures. And it mainly includes the rural land contract management right, rural collective construction land, homestead use rights, forest rights, agricultural machinery ownership and management rights, contracting management rights of water reservoirs and sea and other mortgage business. Also, it can 
establish the service platform of transfer of rural land contract management rights and improve the service network and collateral measures. It can set up a number of guarantee institutions and re-guarantee institutions. And it is based on the government-funded, specializing in agricultural credit guarantee business. It should construct agricultural credit guarantee service network covering rural areas of Nantong.

It should strengthen the construction of agricultural insurance service system, and speed up the formation of policy and commercial insurance institutions. And it should enrich products and build a wide range of protection of significant agricultural insurance system in Nantong. It encourages insurance institutions to increase the intensity of the development of new insurance, such as agricultural target price insurance, weather index insurance, agricultural insurance with characteristics, and so on. It can actively and securely carry out cooperation between insurance and credit institutions. It explores the development of agriculturerelated loans and insurance business. And it establishes and improves the risk mitigation mechanism of agricultural catastrophe.

\section{F. To Strengthen the Construction of Rural Financial Environment}

It further improves the rural financial environment in Nantong. And it can establish and improve the rural credit system. Firstly, it should strengthen the rural credit culture in Nantong. And it also should guide the rural economic entities to firmly establish a sense of honesty and trustworthiness. Then, it cultivates honest and trustworthy financial atmosphere, and strives to create a fair and transparent institution. With the rural cultural construction as the carrier, it can carry out the assessment on credit users, credit village group and credit township in depth. Also, it can make the construction and advocate the social atmosphere of trustworthy glory and dishonesty shame. At the same time, it should combat fraud and malicious evasion of debt behavior, and it can effectively protect the legitimate rights and interests of financial institutions as creditors. Secondly, it should improve the credit rating of the rural economy, establish the scientific and practical credit evaluation index system, and achieve the full coverage of the credit assessment of the main agricultural production with the principle of simpleness, practice and efficiency. Also, it must make the real-time monitoring. Thirdly, it should strengthen the communication between the government departments and financial institutions. Then it can accelerate the construction of the integrated information platform. And in this platform, you can get the information on agricultural policy, agricultural information, and information on the agriculture-related benefits, financial information, and main information on agricultural production and management and other information. In the end, it would achieve the normal sharing of government, banks and agriculture. Fourthly, it should actively concern about the risk of rural production and management, and do the risk prevention and control. According to the subject of loans and ways of guarantee, credit institutions can make supervisory control on the loans. Also, it can make full use of information sharing platform to enhance the management of science and technicalization and automation.

\section{CONCLUSION}

In the future, Nantong should further strengthen the policy guidance and support. And it should solve the following problems. For example, the allocation between urban financial resources and rural financial resources is imbalanced. There are few types of rural financial institutions. The service is single. The financial services and the structure of finance is difficult to meet the needs of the development of modern agriculture. And it has made new progress and breakthroughs in building modern rural financial systems, innovating rural financial systems and improving rural financial services. Then it can promote the development of the rural economy.

\section{REFERENCES}

[1] Research group on rural financial services of the people's bank of China. China Rural Financial Services Report [R]. Beijing: China Financial Press, 2013: 3-85.

[2] Lan Feng. Analysis on rural financial supply and demand system [J]. Agricultural Economics, 2014 (11): 32-33.

[3] Wang Zhao. Analysis on the improvement of rural financial service system in China [J]. China Collective Economy, 2014 (27): 98-99.

[4] Bai Yujuan, Gong Manwei. The financial support and countermeasures in China 's agricultural economic development [J]. Anhui Agricultural Sciences, 2015, (11): 326-327.

[5] Liu Minlou. The influence of rural financial ecology on financial development [J]. Journal of Hunan Agricultural University (Social Science Edition), 2016 (5): 20-26.

[6] Ding Zhiguo, Zhang Yang, Tan Zhaohui. The selection and policy effect of China 's rural financial development [J]. Agricultural Economics, 2016 (1): 68-75. 